\section{Effect of interleukin-1beta and dehydroepiandrosterone on the expression of lumican and fibromodulin in fibroblast-like synovial cells of the human temporomandibular joint}

\author{
K. Okamoto, N. Kiga, Y. Shinohara, \\ I. Tojyo, S. Fujita \\ Department of Oral Maxillofacial Surgery, \\ Wakayama Medical University, Japan
}

\section{Abstract}

Several epidemiological studies have reported that temporomandibular disorders (TMDs) are more prevalent in women than in men. It has recently been proposed that sex hormones such as estrogen, testosterone and dehydroepiandrosterone (DHEA) are involved with the pathogenesis of TMDs. Although studies have investigated the relationship between estrogen and testosterone and the restoration of TMDs, the relationship between DHEA and TMDs is unknown. The synovial tissue of the temporomandibular joint (TMJ) is made up of connective tissue with an extracellular matrix (ECM) composed of collagen and proteoglycan. One proteoglycan family, comprised of small leucine-rich repeat proteoglycans (SLRPs), was found to be involved in collagen fibril formation and interaction. In recent years, the participation of SLRPs such as lumican and fibromodulin in the internal derangement of TMJ has been suggested. Although these SLRPs may contribute to the restoration of the synovium, their effect is still unclear. The purpose of this study was to investigate the effect of DHEA, a sex hormone, on the expression of lumican and fibromodulin in human temporomandibular specimens and in cultured human TMJ fibroblast-like synovial cells in the presence or absence of the pro-inflammatory cytokine interleukin-1beta (IL-1beta). In the in vivo study, both normal and osteoarthritic (OA) human temporomandibular synovial tissues were immunohistochemically examined. In the in vitro study, five fibroblast-like synoviocyte (FLS) cell lines were established from human TMJ synovial tissue of patients with osteoarthritis. The subcultured cells were then incubated for $3,6,12$ or $24 \mathrm{~h}$ with/without IL-1beta (1 $\mathrm{ng} / \mathrm{mL})$ in the presence or absence of DHEA (10 $\mu \mathrm{M})$. The gene expression of lumican and fibromodulin was examined using the real-time polymerase chain reaction (PCR) and their protein expression was examined using immunofluorescent staining. We demonstrated that the expression of lumican differs from that of fibromodulin in synovial tissue and furthermore, that
IL-1beta induced a significant increase in lumican mRNA and immunofluorescent staining in FLS compared to cells without IL-1beta. DHEA plus IL-1beta induced a significant increase in fibromodulin, but not in lumican mRNA, compared to DHEA alone, IL-1beta alone and in the absence of DHEA and IL-1beta. In immunofluorescent staining, weaker fibromodulin staining of FLS cells was observed in cells cultured in the absence of both DHEA and IL-1beta compared to fibromodulin staining of cells cultured with DHEA alone, with DHEA plus IL-1beta, or with IL-1beta alone. These results indicate that DHEA may have a protective effect on synovial tissue in TMJ by enhancing fibromodulin formation after IL-1beta induced inflammation. DHEA enhancement of fibromodulin expression may also exert a protective effect against the hyperplasia of fibrous tissue that TGF-betal induces. In addition lumican and fibromodulin are differentially expressed under different cell stimulation conditions and lumican and fibromodulin may promote regeneration of the TMJ after degeneration and deformation induced by IL-1beta.

\section{Introduction}

Temporomandibular joint disorders (TMDs) are a series of conditions that cause pain and dysfunction in the jaw joint and in the muscles that control jaw movement. The cellular and molecular basis of the pathophysiology of internal derangement (ID) of the temporomandibular joint (TMJ) remain unclear. Synovial inflammation, which is often accompanied by ID of the TMJ, is characterized as hypertrophic synovial tissue based on chronic inflammatory changes. ${ }^{1,2}$ In the presence of synovial inflammation, ID in the TMJ is aggravated, there is denaturation of the posterior disk, connective tissue and synovium; fibrosis and adhesion, denaturation and perforation of the main body of the articular disc. In a recent study, the participation of the metalloproteinases (MMP)-7 and -9 , which play an important role in the extracellular matrix (ECM), has been detected in the $\mathrm{TMJ}^{3}$ and MMPs have been suggested to be involved in TMD-related patient conditions. Furthermore, the small leucine-rich proteoglycans (SLRPs) that are biologically active components of the ECM may contribute to the restoration of the synovium although their effect is still unclear. ${ }^{4}$

Lumican and fibromodulin are class 2 SLRPs that contain primarily keratan sulfate, and, similar to other members of class 2 SLRPs, have 10 leucine rich regions in their central domain. ${ }^{5,6}$ Some studies have shown that lumican is present in tissues such as the cornea, the intervertebral disc and the TMJ discs, and that it plays a significant role in the assembly and regulation of collagen fibers. ${ }^{7-12}$ Lumican that is expressed in injured
Correspondence: Dr. Kenjiro Okamoto, Department of Oral Maxillofacial Surgery, Wakayama Medical University, 811-1 Kimiidera, Wakayama 641-8509, Japan.

Tel/Fax: +81.73.4410643.

E-mail: k-okamo@wakayama-med.ac.jp

Key words: Temporomandibular joint, dehydroepiandrosterone, lumican, fibromodulin, small leucine rich repeat proteoglycan.

Contributions: KO, SF, study design; KO, YS, NK, IT, experimental procedures, immunohistochemical processing, microscopic analysis, data collection and/or preparation of figures; KO, contribution to real-time PCR analysis. All authors have reviewed and contributed to the different draft versions of the manuscript and have read and approved the final manuscript.

Acknowledgments: this work was partly supported by the KAKENHI Grants-in-Aid from the Ministry of Education, Culture, Sports, Science and Technology of the Japanese Government.

Conflict of interest: the authors declare no conflict of interest.

Received for publication: 24 July 2014.

Accepted for publication: 15 January 2015.

This work is licensed under a Creative Commons Attribution NonCommercial 3.0 License (CC BYNC 3.0).

(C) Copyright K. Okamoto et al., 2015 Licensee PAGEPress, Italy

European Journal of Histochemistry 2015; 59:2440 doi:10.4081/ejh.2015.2440

epithelium is reported to modulate cell behavior such as adhesion or migration, thereby contributing to corneal epithelial wound healing. ${ }^{13}$ Furthermore, skin wound healing is significantly delayed in lumican null mice compared to that in wild type mice. ${ }^{14}$ Fibromodulin, which is closely related to lumican, has been reported to be expressed in a number of tissues including the epidermis, intervertebral discs, tendons and the TMJ disc. ${ }^{15-18}$ Growth, aging and degeneration of the intervertebral disc are associated with changes in the abundance and structure of fibromodulin and lumican. ${ }^{10}$ We previously reported that the proteoglycans lumican and fibromodulin are expressed in human TMJ discs and are highly expressed in deformed discs. ${ }^{7}$ Several epidemiological studies have shown that TMDs are more prevalent in women than in men, which suggests that a sex hormone such as estrogen, testosterone or dehydroepiandrosterone (DHEA), plays a role in TMDs. ${ }^{19}$ Although recent studies have shown that estrogen plays important roles in the etiology of TMDs and osteoarthritis (OA) in TMJs, ${ }^{20,21}$ there is little information regarding the relationship between DHEA and TMDs or of that between 
DHEA and OA in the TMJ. DHEA is an adrenal steroid hormone with a wide variety of biological effects. The concentration of DHEA in serum reaches a peak at 25 to 30 years of age and thereafter declines steadily, so that by age 70 , the serum concentration is only $5-10 \%$ of the corresponding value in young adults. Previous studies suggested that DHEA has a protective effect on body functions and against diseases such as bone loss, arthrosclerosis, systemic lupus, cancer and diabetes mellitis. ${ }^{22} \mathrm{~A}$ recent study showed that DHEA protects against articular cartilage loss in the knee. ${ }^{23}$ However, there has so far been no study of the relationship between DHEA and SLRPs in joints and therefore the mechanisms of the effect of DHEA on synovial cells of the TMJ, one of the major cell types in $\mathrm{OA}$, remain unclear. This study aimed to investigate the effect of DHEA on human synovial cells of the TMJ of OA patients after inflammation. We evaluated the expression of lumican and fibromodulin in synovial tissue of $\mathrm{OA}$ patients both in vitro and in vivo.

\section{Materials and Methods}

\section{Immunohistochemical analysis}

\section{Patient characteristics}

Synovial tissues of the TMJ of OA patients (5 cases) and of normal cases (3 cases) were investigated using immunohistochemical analysis. Patients' age ranged from 20 to 72 years, with a mean age of 59.8 years. We treated the patients using conservative treatment and only carried out open surgery on OA patients for whom conservative treatment was unsuccessful. The discs of all five OA patients were macroscopically deformed; none of the discs had a normal biconcave shape and synovial tissues displayed hyperplasia. The three normal discs and synovial tissues were obtained at autopsy. These three patients had died of cancer of the tongue or the breast. The three TMJ discs obtained at autopsy had a normal biconcave shape and all patients had normal synovial tissues. The histologic findings were evaluated on the basis of Gynther's system ${ }^{24}$ which defines synovial lining cell layer hyperplasia in TMJ as more than one or two cell layers. All 5 synovial tissues in the OA patients had moderate or pronounced hyperplasia (3 or more cell layers). In contrast, the 3 normal synovial tissues had a normal score (1 to 2 cell layers). None of the patients had a history of trauma to the mandible or had ankylosis. All patients gave complete informed consent for the surgery and the use of their tissue in the research. This study was approved by the Human Research Ethics Committee, Wakayama Medical University and was in accordance with national ethical standards and with the Helsinki Declaration of 1975 (as revised in 2008).

\section{Immunohistochemistry}

The specimens were fixed overnight in $4 \%$ paraformaldehyde, embedded in paraffin wax, and cut to obtain $5 \mu$ m-thick sections. For immunohistochemical staining, the sections were de-waxed in xylene and rehydrated in serial alcohol. Endogenous peroxidase was blocked by immersing the sections in $0.3 \% \mathrm{H}_{2} \mathrm{O}_{2}$ in methanol for $20 \mathrm{~min}$ at room temperature. The specimens were blocked with $3 \%$ skimmed milk [0.01\% Tween-phosphate-buffered saline (PBS)] for $60 \mathrm{~min}$ at room temperature and were then incubated with rabbit polyclonal antibodies against lumican (1:800 dilution; Wakayama Medical University, Wakayama, Japan) or against fibromodulin (1:400 dilution; University of South Florida, Tampa, FL, USA) at $4^{\circ} \mathrm{C}$ for $12 \mathrm{~h} .{ }^{7}$ After washing with PBS, the specimens were incubated with horseradish peroxidase- labeled anti-rabbit IgG antibody (Dako, Glostrup, Denmark) for 60 min at room temperature. The color was developed using 3,3'diaminobenzidine $/ \mathrm{H}_{2} \mathrm{O}_{2}$ solution followed by counterstaining with Mayer's hematoxylin. The negative controls were subjected to the same protocol except that PBS was used instead of the primary antibody. Each slide was analyzed by two independent observers. The results were evaluated semiquantitatively on four scales: -; no expression, +/-; indistinct expression, +; clear expression, ++ ; high level expression.

\section{Cultivation of fibroblast-like synoviocytes (FLSs) of the TMJ}

Specimens of TMJ were obtained from five OA patients aged $20-70$ years during therapeutic surgery. All patients gave their informed consent. The study was approved by the Ethics Committee of Wakayama Medical University. Synovial tissues of all five cases were cultured. Immediately after removal of the synovial tissue specimens from the TMJ, using sterile instruments and working in a sterile environment, the synovial tissue specimens were washed in PBS (GIBCO/BRL, Gland Island, NY, USA), and placed in Dulbecco's modified Eagle's medium (DMEM; GIBCO/BRL) with $10 \%$ heat-inactivated fetal bovine serum (FBS), 1\% penicillin and streptomycin in a $60 \times 15 \mathrm{~mm}$ culture dish (Falcon; Becton Dickinson and Company, Franklin Lakes, NJ, USA). The tissue samples were incubated at $37^{\circ} \mathrm{C}$ in a humidified $5 \% \mathrm{CO}_{2}$

Table 1. Primers for RT-PCR.

\begin{tabular}{lc} 
Gene & Primers \\
Lumican & F,5'-CCACCACACCTGACAGAGT-3' \\
Fibromodulin & R,5'-CAAGTGATTGACCTCCAGG-3' \\
& F,5'-GGGGCAAGGACTGTTGGAGGAG-3' \\
GAPDH & R,5'-CCAGGTCTGGAGCC-3' \\
& F,5'-GGATGACCTTGCCCACAGCCT-3' \\
\hline
\end{tabular}

atmosphere for 7-14 days and, when they had reached $80 \%$ confluency, the cells were passaged. The culture was continued until the cells had been expanded to 20 dishes $(100 \times 20 \mathrm{~mm})$. All experiments were carried out on cells between passages 4 and 7 . The cells were plated at a density of 1x106/well in 6-well plates (IWAKI, Asahi Techno Glass, Funabashi, Japan) in a medium containing $10 \%$ FBS. The next day, the medium was changed to medium with $10 \%$ certified charcoal stripped FBS (Biological Industries, Kibbutz Beit Haemek, Israel) and incubated for $24 \mathrm{~h}$. The culture plates were then rinsed with PBS and $2 \mathrm{~mL}$ of fresh serum-free medium plus $10 \%$ certified charcoal stripped FBS (Biological Industries) with or without $1 \mathrm{ng} / \mathrm{mL}$ IL-1beta in the presence or absence of $10 \mu \mathrm{M}$ DHEA (Sigma, London, UK) was added. Stock DHEA was dissolved in dimethyl sulfoxide. The cells were then incubated for 3, 6, 12 or $24 \mathrm{~h}$ in a humidified atmosphere under normoxic conditions $\left(20 \% \mathrm{O}_{2}, 5 \% \mathrm{CO}_{2}\right.$ and $\left.75 \% \mathrm{~N}_{2}\right)$. Three independent experiments involving separate cell capture were performed.

\section{Real-time polymerase chain reaction}

Total RNA was isolated from TMJ synovial tissue cells using the RNeasy ${ }^{\circledR}$ Mini Kit (Qiagen, Venlo, The Netherlands), as described in the protocol provided with the kit. First-strand cDNA was synthesized from $1 \mu \mathrm{g}$ of total RNA using the SuperScript III ${ }^{\circledR}$ transcriptase (Invitrogen, Carslbad, CA, USA). The reactions were primed with Oligo (dT) primers and the total volume was $10 \mu \mathrm{L}$. RT-PCR was performed using the BIO-RAD iCycler $\mathrm{iQ}$ system (Bio Rad, Hercules, CA, USA) according to the manufacturer's instructions. The reactions were performed in a total volume of $20 \mu \mathrm{L}$ using the $\mathrm{iQ}$ SYBR Green Supermix (Bio Rad); $1 \mu \mathrm{L}$ of cDNA sample was used as a template. Cycling was started with an activation step of $95^{\circ} \mathrm{C}$ for $3 \mathrm{~min}$, and the amplification program was repeated 40 times (denaturation: $95^{\circ} \mathrm{C}$ for $10 \mathrm{~s}$; annealing: $55^{\circ} \mathrm{C}$ for $10 \mathrm{~s}$; extension: $72^{\circ} \mathrm{C}$ for $30 \mathrm{~s}$ ) with fluorescence measurement at $72^{\circ} \mathrm{C}$. All samples were run in triplicate with the internal control (GAPDH RNA) and the target gene (Table 1) on the same plate. The fluorescence threshold value was calculated using the iCycle iQ system software version 3.0A. To confirm amplification specificity, the PCR products from each primer pair were 
subjected to a melting curve analysis. Real-time PCR efficiencies for each reaction were calculated using the formula Efficiency $(\mathrm{E})=10^{[-1 / \mathrm{slope}]}$, from the slope values given in the iCycle $\mathrm{iQ}$ system software. The $\mathrm{C}_{t}$ values for the reference gene $(G A P D H)$ and the target gene were calculated by subtracting the value of the experimental group (normal or DHEA or
DHEA/L-1beta or IL-1). The mathematical model presented by Pfaffl was used to determine the relative quantification of the target gene in comparison to the reference gene. The relative expression ratio (R) of the target gene was calculated based on $\mathrm{E}$ and the $\mathrm{Ct}$ of the experimental group versus the control, and is expressed in comparison to GAPDH RNA.

\section{Immunofluorescent staining of FLS}

Differences in the expression of lumican or fibromodulin in FLSs in response to DHEA and/or IL-1beta were examined using immunofluorescence staining. FLS cells were cultured and treated as described for q-PCR. Cells were seeded at $10,000 \mathrm{cel} / \mathrm{cm}^{2}$ in a chamber slide and were grown
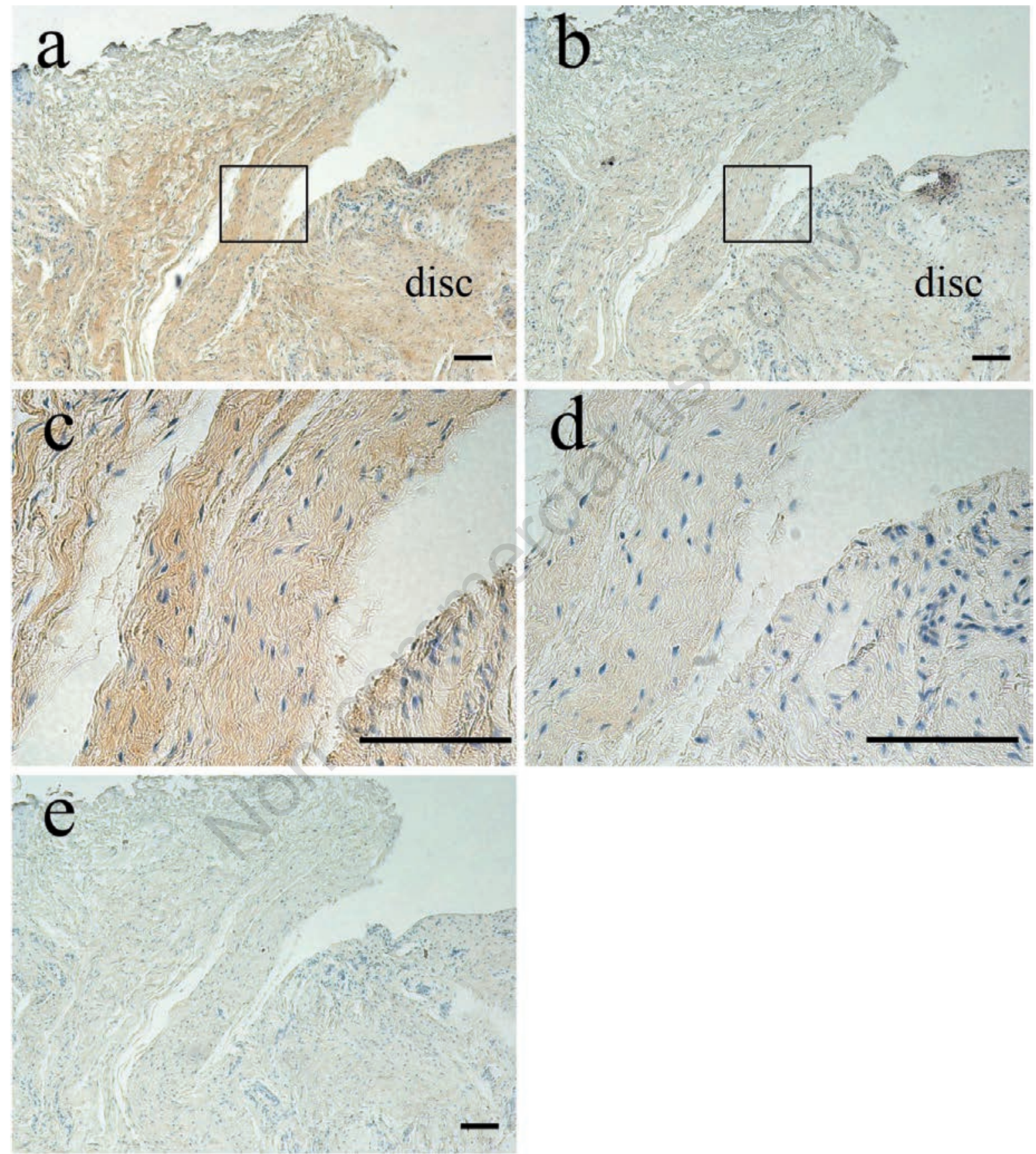

Figure 1. Immunohistochemical staining of lumican and fibromodulin expression in hypertrophic synovial tissue in the temporomandibular joint (TMJ) of ostheoarthritic (OA) patients. a) Immunohistochemical staining of lumican (LUM) expression in hypertrophic synovial tissue in the TMJ of OA patient. b) Immunohistochemical staining of fibromodulin (FM) expression in hypertrophic synovial tissue in the TMJ of OA patients. c) Higher magnification of the boxed area shown in panel a. d) Higher magnification of the boxed area shown in panel b. e) Negative control (omission of first antibody) for the immunohistostaining of LUM and FM in hypertrophic synovial tissue in the TMJ of OA patients. Scale bars: $100 \mu \mathrm{m}$. 
for $24 \mathrm{~h}$. The chamber slides were rinsed with PBS and $2 \mathrm{~mL}$ of fresh serum-free medium with $10 \%$ certified charcoal stripped FBS (Biological Industries) with or without $1 \mathrm{ng} / \mathrm{mL}$ IL-1beta in the presence or absence of $10 \mu \mathrm{M}$ DHEA (Sigma) was added, and the cells were grown for $24 \mathrm{~h}$. Monensin ( $2 \mu \mathrm{M}$; BioLegend, San Diego, CA, USA) was added to the culture for the last $3 \mathrm{~h}$. Cells were then fixed for $5 \mathrm{~min}$ using $4 \%$ paraformaldehyde. Non-specific binding was blocked with $3 \%$ skimmed milk ( $0.01 \%$ TweenPBS) for $30 \mathrm{~min}$ at room temperature. The cells were then incubated overnight with anti-lumican or anti-fibromodulin polyclonal antibodies (Santa Cruz Biotechnology, Santa Cruz, CA, USA) at 1:100 dilution, followed by the appropriate secondary antibody for $60 \mathrm{~min}$. Alexa Fluor 488-labelled antirabbit as secondary antibodies (Invitrogen) were used according to the host species of primary antibody. Concurrently, as an internal control, all cells were incubated with the anti-glyceraldehyde-3phosphate dehydrogenase (GAPDH) antibody as primary antibody (Santa Cruz Biotechnology) at 1:100 and Alexa Fluor 546-labelled anti-goat as secondary antibodies (Invitrogen) were used according to the host species of the primary antibody. Between all stages of the staining process, the cells were washed three times with PBS for 5 min each time. In all cases, appropriate control slides were also prepared. The negative controls were subjected to the same protocol except for the omission of the primary antibody. The cover slides were mounted onto chamber slides and viewed under an erecting-type vertical-light fluorescent microscope (Eclipse E800; Nikon, Tokyo, Japan) equipped with a digital camera (dmx1200C; Nikon) to acquire and analyze computerized images by ACT-1C for dxm1200c software. Each slide was analyzed by two independent observers. The results were evaluated semiquantitatively on 2 scales: no score; below moderate expression, +; higher expression.
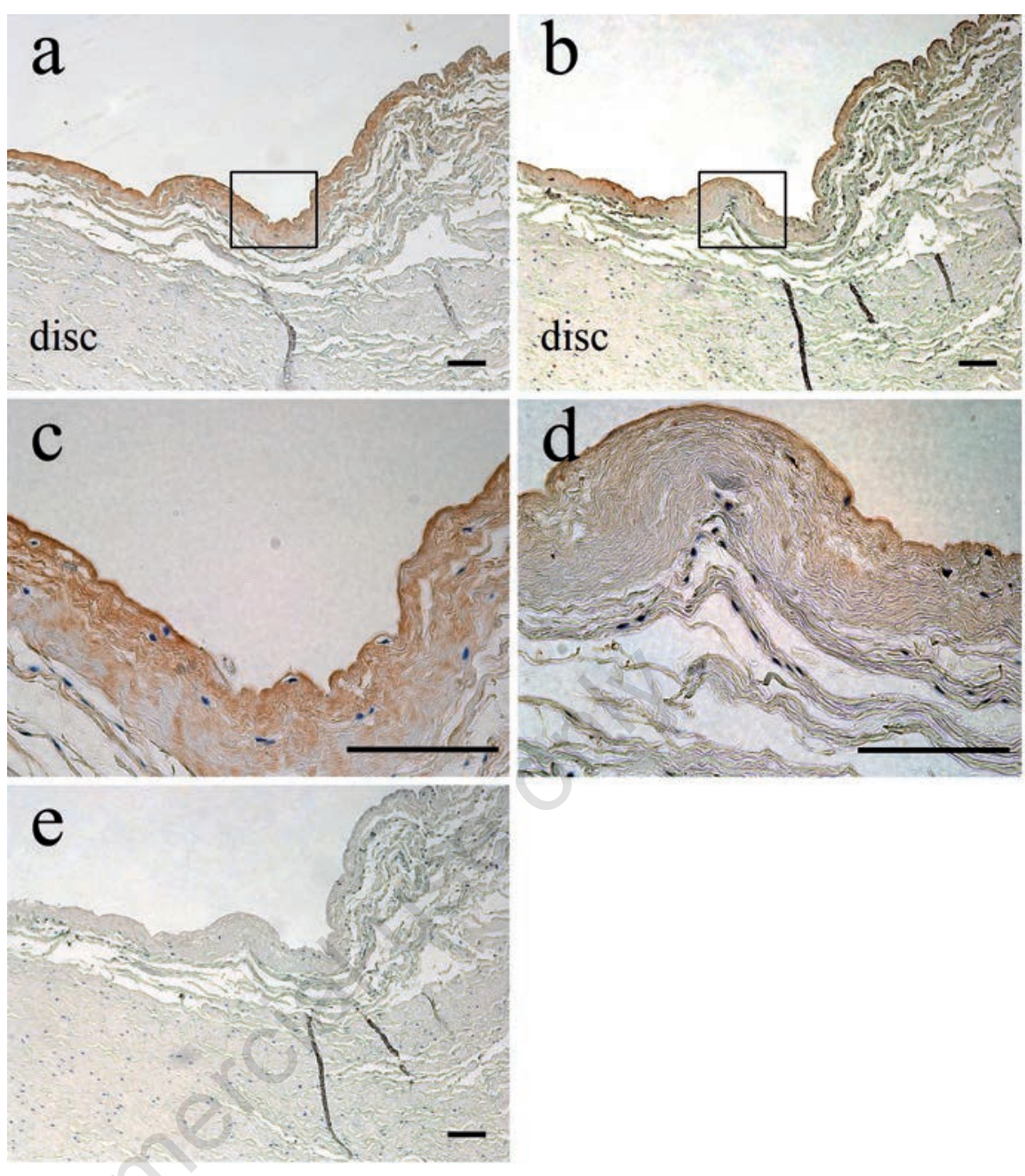

Figure 2. Immunohistochemical staining of lumican and fibromodulin expression in normal synovial tissue of the temporomandibular joint (TMJ). a) Immunohistochemical staining of lumican (LUM) expression in normal synovial tissue of the TMJ. b) Immunohistochemical staining of fibromodulin (FM) expression in normal synovial tissue of the TMJ. c) Higher magnification of the boxed area shown in panel a.d) Higher magnification of the boxed area shown in panel b. e) Negative control (omission of first antibody) for immnohistostaining of LUM and FM in normal synovial tissue of the TMJ. Scale bars: $100 \mu \mathrm{m} .$.

Table 2. Patients' characteristics.

\begin{tabular}{|c|c|c|c|c|c|c|c|}
\hline Sample no. & Sex & $\begin{array}{c}\text { Age } \\
\text { (years) }\end{array}$ & Diagnosis & Symptom & $\begin{array}{l}\text { Displacement } \\
\text { of TMJ disc }\end{array}$ & $\begin{array}{l}\text { Lumican detection } \\
\text { in synovial tissue }\end{array}$ & $\begin{array}{l}\text { Fibromodulin } \\
\text { detection in synovial tissue }\end{array}$ \\
\hline 1 & Male & 61 & Normal & - & - & ++ & + \\
\hline 2 & Female & 61 & Normal & - & - & + & + \\
\hline 3 & Female & 70 & Normal & - & - & + & $+/-$ \\
\hline 4 & Female & 20 & ID-OA & + & + & ++ & - \\
\hline 5 & Male & 64 & ID-OA & + & + & ++ & - \\
\hline 6 & Female & 72 & ID-OA & + & + & + & + \\
\hline 7 & Male & 72 & ID-OA & + & + & + & - \\
\hline 8 & Female & 58 & ID-OA & + & + & + & - \\
\hline
\end{tabular}

TMJ, temporomandibular joint; ID, internal derangement; OA, osteoarthritis. 


\section{Statistical analysis}

Three independent experiments involving separate cell capture, RNA extraction and reverse transcription were performed. All values are expressed as means of the three experiments $( \pm$ SD) Statistical significance was evaluated by multiple-comparison tests (Tukey-Kramer). A P-value less than 0.05 was considered as significant.

\section{Results}

\section{Immunohistochemical analysis of lumican and fibromodulin in syn- ovial tissue of the TMJs of OA patients and of normal TMJs}

We first compared the protein expression of lumican and fibromodulin in normal and $\mathrm{OA}$ synovial tissue of TMJs using immunohistochemistry. The discs of $\mathrm{OA}$ patients did not have a normal shape and their synovial tissue displayed hyperplasia. The subsynovial tissue showed mild granulation. High lumican expression was observed over a large area of synovial tissue and subsynovial tissue, whereas little fibromodulin expression was observed in OA synovial tissue (Figure 1). Normal discs had a normal biconcave shape (not shown) and normal synovial tissue did not display hyperplasia. High lumican expression was observed over a large area of normal synovial tissue. Although a statically significant difference was not demonstrated, synovial tissues in OA displays a tendency for weaker fibromodulin expression than normal superficial synovial tissue (Figure 2, Table 2).

Effect of DHEA treatment on lumican and fibromodulin expression in temporomandibular synovial cells

Real-time polymerase chain reaction assay

To evaluate the potential contribution of lumican and fibromodulin to TMJ synovial tissue disruption during inflammation and the role of DHEA in this process, FLS cells were treated with or without $1 \mathrm{ng} / \mathrm{mL}$ of the pro- inflammatory cytokine IL-1beta in the presence or absence of $10 \mu \mathrm{M}$ DHEA over $24 \mathrm{~h}$.

\section{mRNA expression of lumican}

IL-1beta alone, and DHEA plus IL-1beta, induced a significant increase in lumican mRNA after $12 \mathrm{~h}$ incubation compared to its level in cells grown in the absence of DHEA and IL-1beta or in cells grown with DHEA alone $(\mathrm{P}<0.01)$ (Figure 3$)$.
mRNA expression of fibromodulin

DHEA plus IL-1beta induced a significant increase in fibromodulin mRNA after $12 \mathrm{~h}$ incubation compared to its level in cells grown in the absence of DHEA and IL-1beta $(\mathrm{P}<0.01)$, or in cells grown with DHEA alone $(\mathrm{P}<0.05)$ or with IL-beta alone $(\mathrm{P}<0.05)$. IL-1beta alone induced a significant increase in fibromodulin mRNA after $12 \mathrm{~h}$ compared to its level in cells grown in the absence of DHEA and IL-1beta

\section{3 h Lumican}

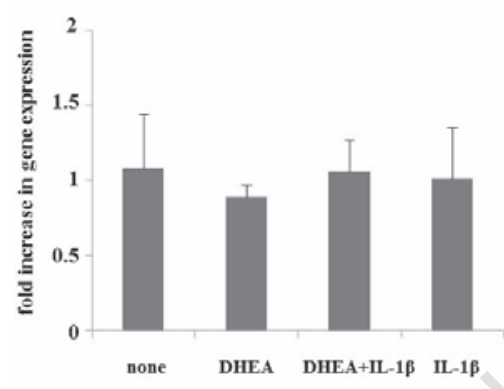

12 h Lumican

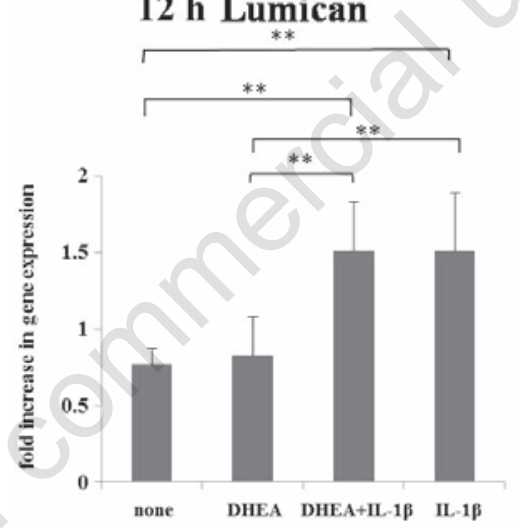

$6 \mathrm{~h}$ Lumican

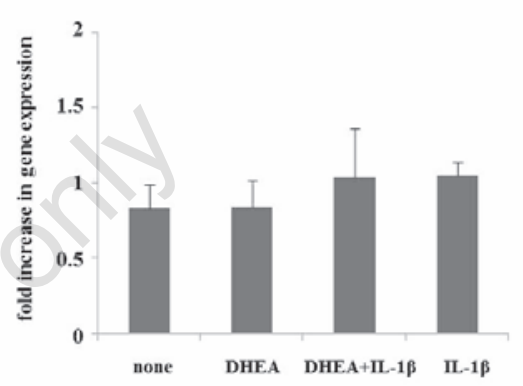

$24 \mathrm{~h}$ Lumican

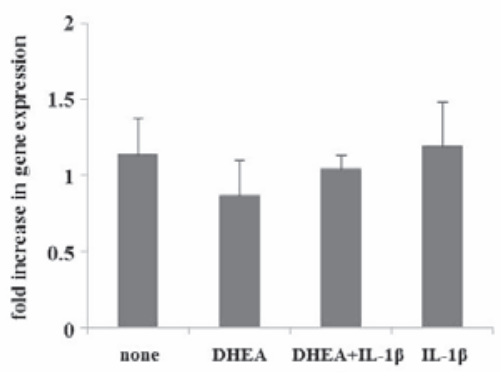

Figure 3. Real-time PCR analysis of the effect of DHEA with/without IL-1beta on lumican expression in FLS cells of OA TMJs over time. FLS cells of the TMJ of OA patients were cultured for 3, 612 or $24 \mathrm{~h}$ with DHEA $(10 \mu \mathrm{M})$, DHEA $(10 \mu \mathrm{M})$ plus IL-1beta $(1$ $\mathrm{ng} / \mathrm{mL})$ or with IL-1beta $(1 \mathrm{ng} / \mathrm{mL}$ ), or were left untreated (none). Real-time PCR was then performed to evaluate the expression of lumican. IL-1beta alone, and DHEA plus IL-1beta, induced a significant increase in lumican mRNA after $12 \mathrm{~h}$ incubation compared to its level in cells grown in the absence of DHEA and IL-1beta or in cells grown with DHEA alone $(\mathrm{P}<0.01)$. ${ }^{*} \mathrm{P}<0.05,{ }^{* *} \mathrm{P}<0.01$.

Table 3. Immunofluorescence analysis.

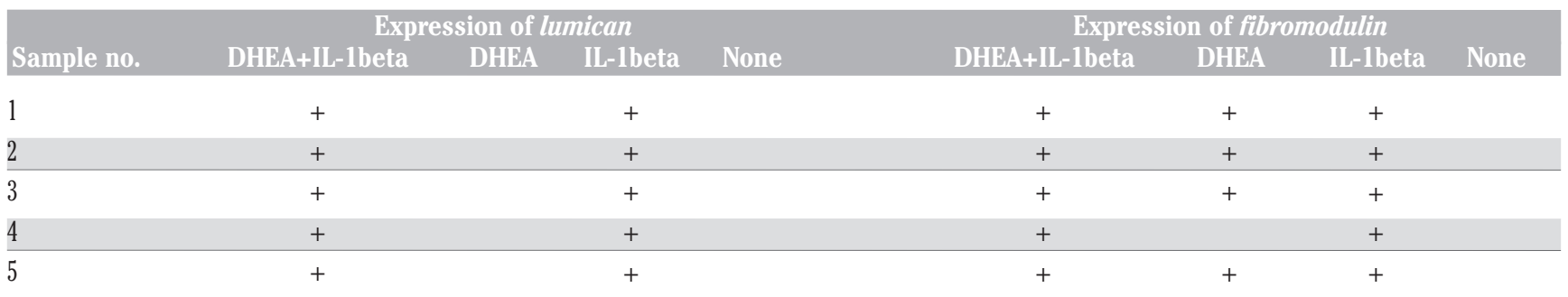

Differences in the expression of lumican or fibromodulin in FLSs in response to DHEA and/or IL-lbeta: no score, below moderate expression; +, higher expression. 
$(\mathrm{P}<0.01)$. After $24 \mathrm{~h}$ incubation, DHEA plus ILlbeta induced a significant increase in fibromodulin mRNA compared to its level in cells grown in the other groups $(\mathrm{P}<0.05)$ (Figure 4).

\section{Immunofluorescent staining of FLSs}

Lumican and fibromodulin protein expression in the FLS cells in human OA TMJ synovial tissues that were treated with or without IL-1beta in the presence or absence of DHEA was analyzed using immunofluorescence (Figure 5 and Figure 6). A similar pattern of staining was observed for lumican and fibromodulin following all treatments. Thus, a small amount of lumican and fibromodulin was observed inside the nuclear envelope, and more intense staining was observed around the nucleus. Lower lumican staining was observed in FLS cells in the absence of IL1beta, regardless of the presence or absence of DHEA, than in the presence of IL-1 beta. Weaker fibromodulin staining of FLS cells was observed in cells cultured in the absence of DHEA or IL-1beta compared to fibromodulin staining of cells cultured with DHEA alone, with DHEA plus IL-1beta, or with IL-1beta alone (Figure 5 and Figure 6; Table 3).

\section{Discussion}

A previous study indicated that lumican and fibromodulin display differential expression in response to cell stimulation and that lumican may promote the regeneration of TMJ discs after degeneration and deformation induced by IL-1beta. ${ }^{7}$. However, there has been no study concerning the relationship between these SLRPs and DHEA.

In the present study, we performed both in vitro and in vivo studies of TMJ synovial tissue from $0 A$ patients and normal cases. Using immunohistochemistry we demonstrated that lumican and fibromodulin are expressed in TMJ synovial tissue. Lumican expression was observed in both normal synovial tissue and in the synovial tissue of $\mathrm{OA}$ patients whereas fibromodulin expression tended to be observed higher in normal synovial tissues. In vitro, ILlbeta enhanced both lumican and fibromodulin expression and DHEA enhanced fibromodulin, but not lumican expression at both the mRNA and protein level in the presence of IL1beta. The formation of DHEA by the adrenal glands is dramatically reduced during aging. For this reason, DHEA seems to be associated with age-related diseases such as atherosclerosis, insulin resistance and obesity. ${ }^{25}$ With regards to the TMJ, Castelli has stated that one of the most significant histopathological findings in temporomandibular joints of aged indi- viduals are intense fibrocartilaginous proliferations of the condylar head and articular eminence linings and proliferation of the synovial pannus and subsynovial tissue. ${ }^{26}$ These findings are similar in some aspect to the finding of OA in TMJ. It is known that involvement of the synovial tissue of $0 \mathrm{~A}$ in the TMJ is characterized by a proliferative phase and a late fibrous phase. Dijkgraaf et al. suggested that the intense and prolonged fibrous phase may not be a normal appropriate response to the initial insult but rather an aberrant counterproductive response in the TMJ. ${ }^{2}$ In the present study, synovial tissues of OA displayed fibrous hyperplasia compared to synovial tissues of normal cases. DHEA may have either a direct effect or an indirect effect on cells. The indirect effect is mediated through its conver- sion to estrogen and/or testosterone in peripheral target tissues. ${ }^{25}$ There has been no report on the effect of DHEA or testosterone on SLRPs, although Mickiewicz et al. have reported that the absence of estrogen results in decreased expression of lumican and fibromodulin. ${ }^{27}$ Regarding the role of lumican and fibromodulin in collagen fibril organization, it is known that lumican, which is a protein that is highly expressed in connective tissue, has the ability to regulate collagen fibril organization and accelerate mouse skin wound healing. ${ }^{14}$ In TMJ synovial tissue, lumican is expressed at the synovial surface that receives mechanical stress and in hypertrophic synovial tissue. Honardoust et al. have proposed that fibromodulin is significantly down-regulated in hypertrophic scars. ${ }^{28,29}$ The result of the

\section{3 h Fibromodulin}

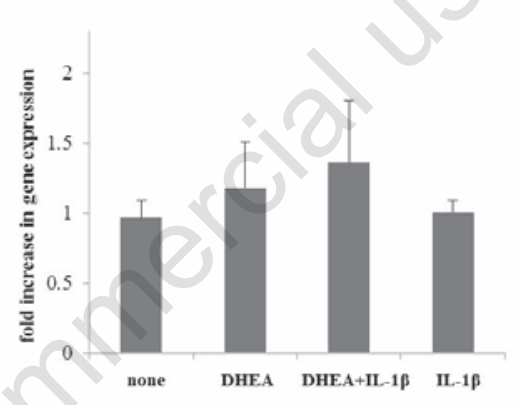

12 h Fibromodulin

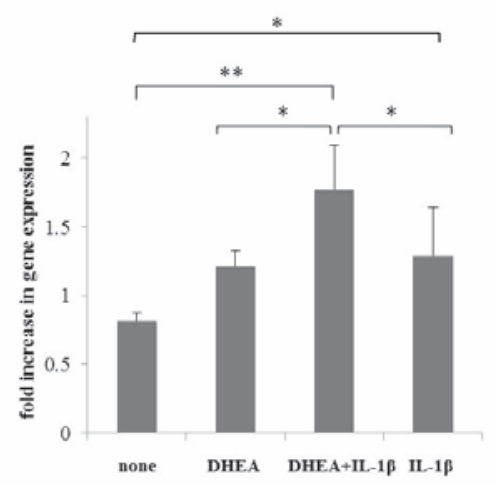

$6 \mathrm{~h}$ Fibromodulin

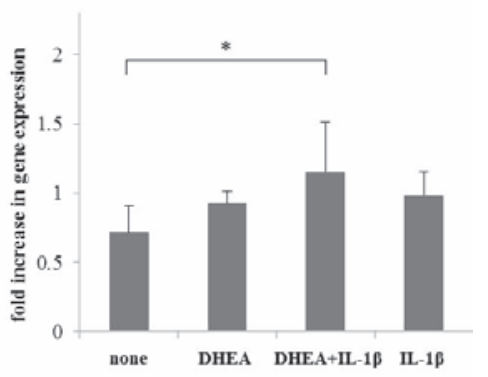

24 h Fibromodulin

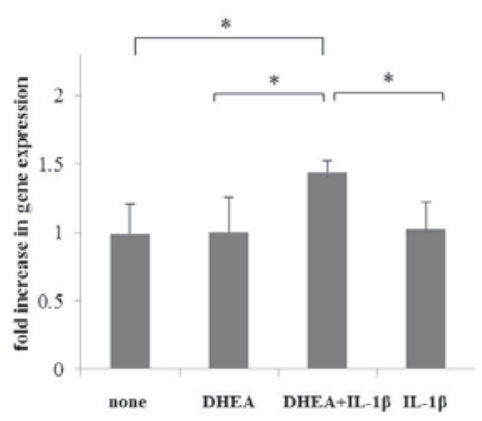

Figure 4. Real-time PCR analysis of the effect of DHEA with/without IL-1beta on fibromodulin expression in FLS cells of OA TMJs over time. FLS cells of the TMJ of OA patients were cultured for 3,612 or $24 \mathrm{~h}$ with DHEA $(10 \mu \mathrm{M})$, DHEA $(10 \mu \mathrm{M})$ plus ILlbeta $(1 \mathrm{ng} / \mathrm{mL})$ or with IL-1beta $(1 \mathrm{ng} / \mathrm{mL})$, or were left untreated (none). DHEA plus IL-1beta induced a significant increase in fibromodulin mRNA after $12 \mathrm{~h}$ incubation compared to its level in cells grown in the absence of DHEA and IL-1beta $(P<0.01)$, or in cells grown with DHEA alone $(P<0.05)$ or with IL-beta alone $(P<0.05)$. IL-1beta alone induced a significant increase in fibromodulin mRNA after $12 \mathrm{~h}$ compared to its level in cells grown in the absence of DHEA and IL-1beta $(\mathrm{P}<0.01)$. After $24 \mathrm{~h}$ incubation, DHEA plus IL-1beta induced a significant increase in fibromodulin mRNA compared to its level in cells grown in the other groups $(P<0.05) .{ }^{*} P<0.05,{ }^{* *} \mathrm{P}<0.01$. 

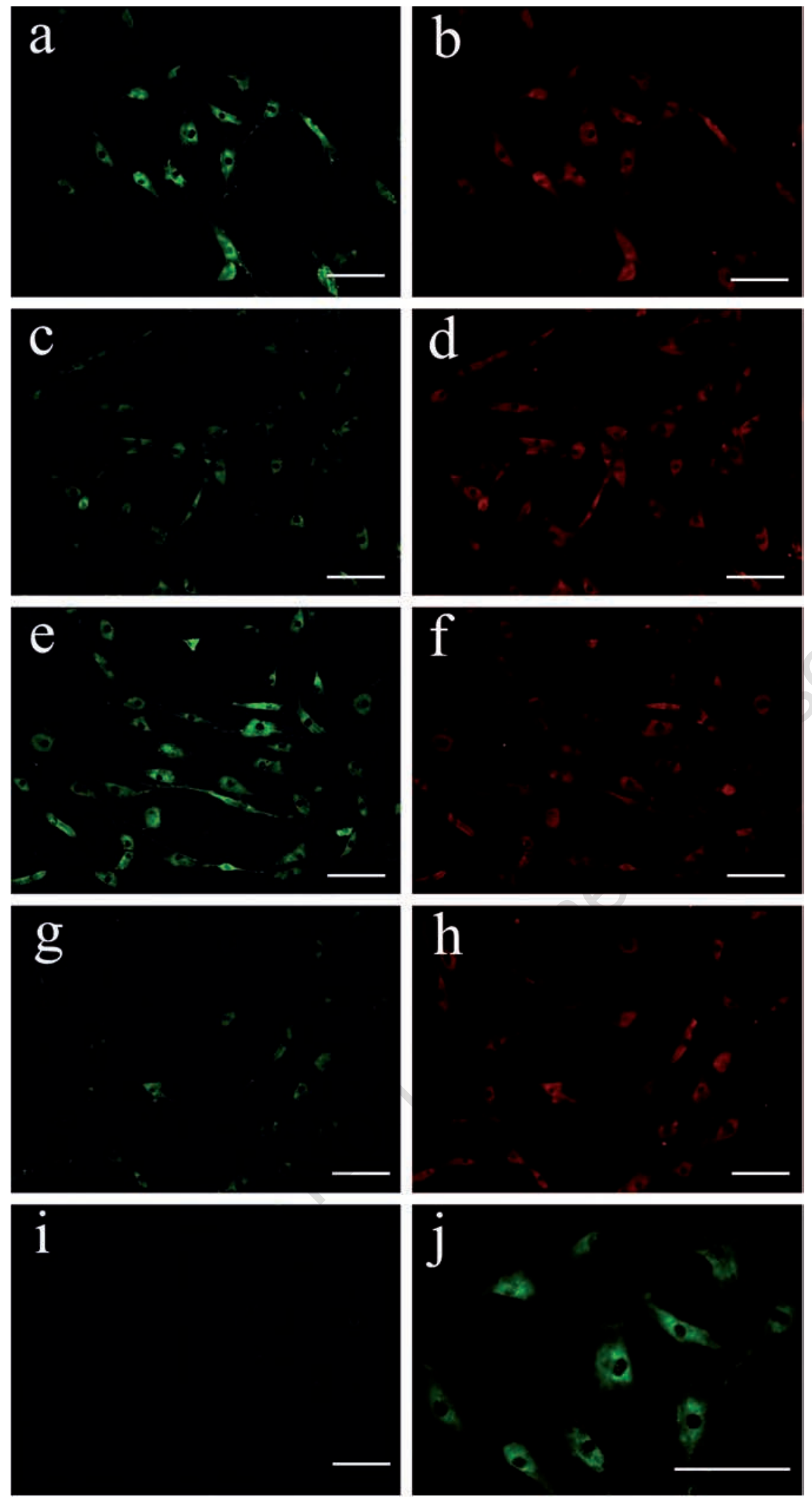

Figure 5. Immunofluorescent staining of the effect of DHEA with/without IL-1beta on lumican (LUM) expression in FLS cells of OA TMJs. a,c,e,g) Immunofluorescent staining of LUM expression. b,d,f,h) Immunofluorescent staining of internal control GAPDH expression. a,b) DHEA $(10 \mu \mathrm{M})$ plus IL-1 $\beta(1 \mathrm{ng} / \mathrm{mL})$. c,d) DHEA $(10 \mu \mathrm{M})$ alone. e,f) IL-1 $\beta(1 \mathrm{ng} / \mathrm{mL})$ alone. $\mathrm{g}, \mathrm{h})$ No treatment. i) Negative control (omission of first antibody) for immunofluorescent staining of LUM in FLS cells of OA TMJs. Scale bars: a-i) $100 \mu \mathrm{m}$. j) Higher magnification of panel a. present study, hypertrophic synovial tissue in OA displays a tendency for weaker fibromodulin expression than normal synovial tissue, has much in common with their conclusion regarding the hyperplasia of fibrous tissue. In addition, we demonstrated that IL-1beta induces a significant increase in lumican and fibromodulin mRNA and in their protein expression as assessed using immunofluorescence after 12-24 h culture compared to cells cultured without IL-1beta in vitro. These results indicate that although lumican and fibromodulin expression is localized differently in OA and normal synovial tissues, enhancement of the expression of lumican and fibromodulin may promote the regeneration of TMJ synovial tissue after degeneration and deformation induced by IL-1beta. In contrast, DHEA enhances fibromodulin, but not lumican expression at the mRNA and protein level following IL-1beta administration. After $24 \mathrm{~h}$ incubation, DHEA plus IL-1beta induced a significant increase in fibromodulin mRNA compared to its level in cells grown in the other treatment groups, although there were no differences in the amount of fibromodulin protein detected by immunofluorescence between FLS cells treated with DHEA plus IL-1beta and cells treated with IL-1beta only or with DHEA only. Based on a review of the literature, it is possible that the degeneration of lumican that is modulated by DHEA may be different from the degeneration of fibromodulin. The matrix metalloprotease (MMP)-13 can degrade SLRPs and MMP-13 has been detected in TMDs. Monfort $e t$ al. have proposed extensive MMP13 cleavage of fibromodulin, but only minimal cleavage of lumican. ${ }^{30}$ Li et al. have stated that DHEA decreases MMP-13 gene expression. ${ }^{31}$ Thus, expression of fibromodulin may be increased by a DHEA-mediated decrease in MMP-13. However, the relationship between DHEA and SLRPs has not been investigated to date. In conclusion, it is likely that DHEA enhances the expression of fibromodulin in inflammation induced by IL-1beta. Fibromodulin can bind to and inhibit TGFbetal activity in vivo and in vitro. ${ }^{32,33}$ Since TGF-betal induces fibroblasts to synthesize and induce the contraction of extracellular matrix, this cytokine has long been believed to be a central mediator of the fibrotic response. By enhancing fibromodulin expression, DHEA may exert a protective effect against the hyperplasia of fibrous tissue that TGF-betal induces. In clinical problems with TMJs, one serious situation where inflammation and fibrous tissue hyperplasia occur simultaneously is fibrous ankylosis after trauma of operation on the TMJ. ${ }^{34}$ Although the mechanism of fibrous ankylosis has not yet been revealed, DHEA may protect against hypertrophic synovial tissue and fibrous ankylosis through an antifibrotic 

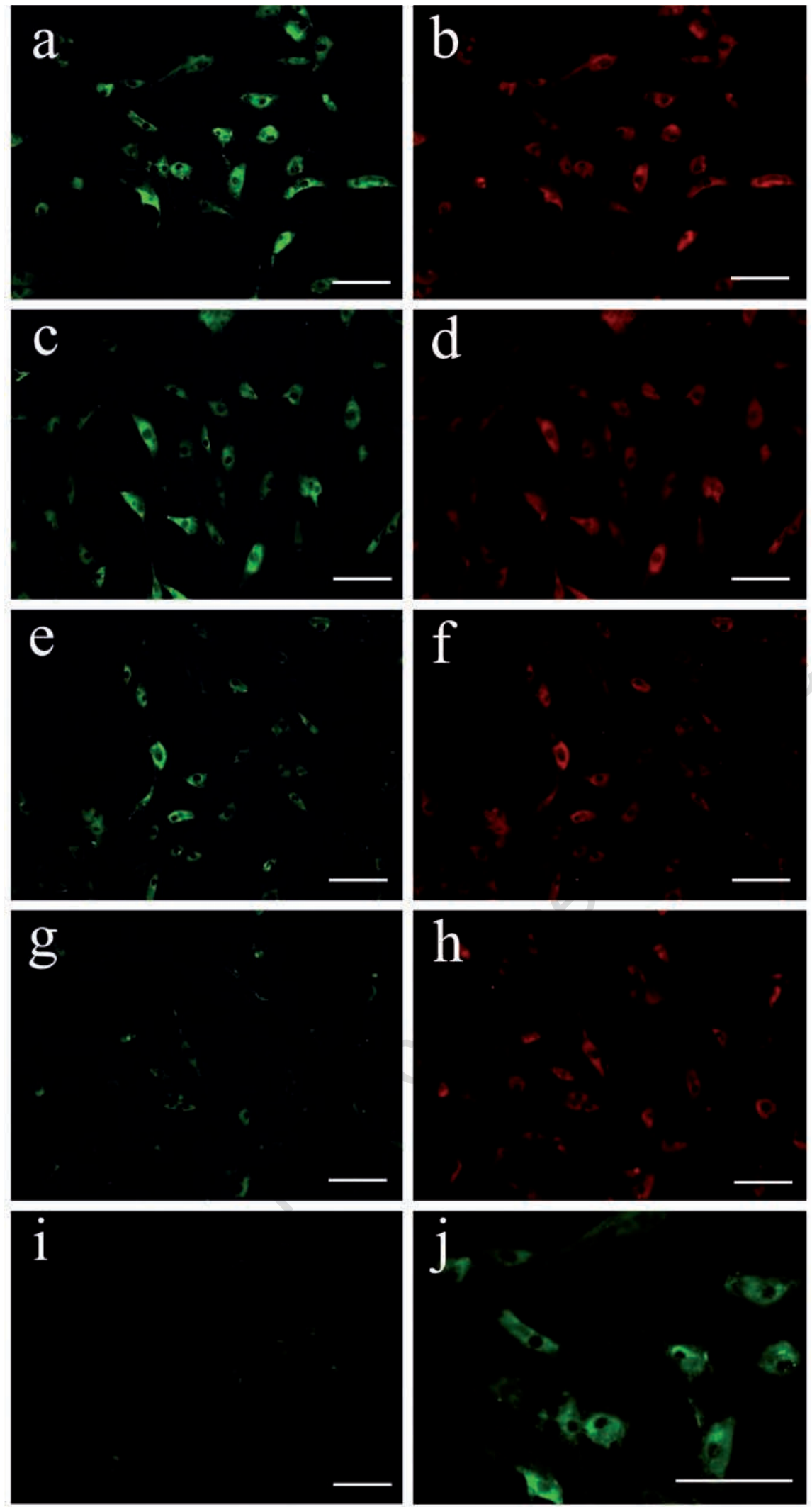

Figure 6. Immunofluorescent staining of the effect of DHEA with/without IL-1beta on fibromodulin (FM) expression in FLS cells of OA TMJs. a,c,e,g) Immunofluorescent staining of FM expression. b,d,f,h) Immunofluorescent staining of internal control GAPDH expression. a,b) DHEA $(10 \mu \mathrm{M})$ plus IL-1 $\beta(1 \mathrm{ng} / \mathrm{mL})$. c,d):DHEA $(10 \mu \mathrm{M})$ alone. e, f) IL-1 $\beta(1 \mathrm{ng} / \mathrm{mL}$ ) alone. g,h) None. i) Negative control (omission of first antibody) for immunofluorescent staining of FM in FLS cells of OA TMJs. Scale bars: a-i) $100 \mu \mathrm{m}$. j) Higher magnification of panel a. effect. Since DHEA has been detected in various body regions in humans, this finding contributes not only to the study of TMJs, but also to whole body studies. However, the mechanisms of the DHEA effects on synovial cells of the TMJ also remain unclear. Further studies regarding both SLRP and DHEA in the TMJ are required.

\section{References}

1. Carls FR, von Hochstetter, Makek M, Engelke W. Diagnostic accuracy of TMJ arthroscopy in correlation to histological finding. J Craniomaxillofac Surg 1995;23: 75-80.

2. Dijkgraaf LC, Leim RS, de Bont LG. Synovial membrane involvement in osteoarthritic temporomandibular joint: a light microscopic study. Oral Surg Oral Med Oral Radiol Endod 1997;83:373-86.

3. Loreto C, Leonardi R, Musumeci G, Pannone G, Castorina S. An ex vivo study on immunohistochemical localization of MMP-7 and MMP-9 in temporomandibular joint discs with internal derangement. Eur J Histochem 2013;57:e12.

4. Monfort J, Tardif G, Roughley P, Reboul P, Boileau C, Pelletier JP, et al. Identification of opticin, a member of the small leucinrich repeat proteoglycan family, in human articular tissues: a novel target for MMP13 in osteoarthritis. 0steoarthritis Cartilage 2008;16:749-75.

5. Halper J. Proteoglycans and diseases of soft Tissues. Adv Exp Med Biol 2014;802: 49-58.

6. Schaefer L, Iozzo RV. Biological functions of the small leucin-rich proteoglycans: From genetics to signal transduction. J Biol Chem 2008;283:21305-9.

7. Kiga N, Tojyo I, Matsumoto T, Hiraishi Y, Shinohara Y, Makino S, et al. Expression of lumican and fibromodulin following interleukin-1 beta stimulation of disc cells of the human temporomandibular joint. Eur J Histochem 2011;55:e11.

8. Scott JE. Supramolecular organization of extracellular matrix glycosaminoglycans, in vitro and in the tissues. FASEB J. 1992;6:2639-45.

9. Funderburgh JL, Funderburgh ML, Brown SJ, Vergnes JP, Hassell JR, Mann MM, et al. Sequence and structural implications of a bovine corneal keratan sulfate proteoglycan core protein. J Biol Chem 1993;268: 11874-80.

10. Sztrolovics R, Alini M, Mort JS, Roughley PJ. Age-related changes in fibromodulin and lumican in human intervertebral discs. Spine (Phila Pa 1976) 1999;24:1765-71. 
11. Gill MR, Oldberg A, Reinholt FP Fibromodulin-null murine knee joints display increased incidences of osteoarthritis and alterations in tissue biochemistry. Osteoarthritis Cartilage 2002;10:751-7

12. Raouf A, Ganss B, McMahon C, Vary C, Roughley PJ, Seth A. Lumican is a major proteoglycan component of the bone matrix. Matrix Biol 2002;21:361-7.

13. Saika S, Shiraishi A, Saika S, Lin CW, Funderburgh JL, Kao CW, et al. Role of lumican in the corneal epithelium during wound healing. J Biol Chem 2000;275: 2607-12.

14. Yeh JT, Yer LK, Jung SM, Chang TJ,Wu HH, Shiu TF, et al. Impaired skin wound healing in lumican-null mice. Br J Dermatol 2013;163:1174-80.

15. Melrose J, Smith SM, Fuller ES, Young AA, Roughley PJ, Dart A, et al. Biglycan and fibromodulin fragmentation correlates with temporal and spatial annular remodeling in experimentally injured ovine intervertebral discs. Eur Spine J 2007;16:2193-205.

16. Vélez-Delvalle C, Marsch-Moreno $\mathrm{M}$, Castro-Muñozledo F, Bolivar-Flores YJ, KuriHarcuch W. Fibromodulin gene is expressed in human epidermal keratinocytes in culture and in human epidermis in vivo. Biochem Biophys Res Commun 2008;371:420-4.

17. Embree MC, Kilts TM, Ono M, Inkson CA, Syed-Picard F, Karsdal MA, et al. Biglycan and fibromodulin have essential roles in regulating chondrogenesis and extracellular matrix turnover in temporomandibular joint osteoarthritis. Am J Pathol 2010;176: $812-26$.

18. Kilts T, Ameye L, Syed-Picard F, Ono M, Berendsen AD, Oldberg A, et al. Potential roles for the small leucine-rich proteoglycans biglycan and fibromodulin in ectopic ossification of tendon induced by exercise and in modulating rotarod performance. Scand J Med Sci Sports 2009;19:536-46.

19. Wang XD, Kou XX, Meng Z, Bi RY, Liu Y, Zhang JN, et al. Estrogen aggravates lodoacetate-induced temporomandibular joint osteoarthritis. J Dent Res 2013;92: 918-24.

20. Kou XX, Wu YW, Ding Y, Hao T, Bi RY, Gan $\mathrm{YH}$, et al. 17 $\beta$-Estradiol aggravates temporomandibular joint inflammation through the NF- $\mathrm{B}$ pathway in ovariectomized rats. Arthritis Rheum 2011;63:1888-97.

21. Galal N, El Beialy W, Deyama Y, Yoshimura Y, Yoshikawa T, Suzuki K, et al. Effect of estrogen on bone resorption and inflammation in the temporomandibular joint cellular elements. Int J Mol Med 2008;21: 785-90.

22. Wu LD, Yu HC, Xiong Y, Feng J. Effect of dehydroepiandrosterone on cartilage and synovium of knee joints with osteoarthritis in rabbit. Rumatol Int 2006;27:79-85.

23. Huang K, Zhang C, Zang XW, Bao JP. Effect of dehydroepiandrosterone on aggrecanase expression in articular cartilage in a rabbit model of osteoarthritis. Mol Biol Rep 2011;38:3569-72.

24. Gynther GW, Holmlund AB, Reinholt FP. Synovitis in internal derangement of the temporomandibular joint: correlation between arthroscopic and histologic findings. J Oral Maxillofac Surg 1994; 52:913-7.

25. Labrie F, Luu-the V, Bélanger A, Lin SX, Simard J, Pelletier G, et al. Is dehydroepiandrosterone a hormone? J Endocrinol 2005;187:169-96.

26. Castelli W.A, Nasjleti C.E, Diaz-Perez R, Caffesse RG. Histopathologic finding in temporomandibular joints of aged individuals. J Prosthet Dent 1985;53:415-9.

27. Mickiewicz M, Asano Y, Znoyko S, Gong Y, Watson DK, Trojanowska M. Distinct effects of gonadectomy in male and female mice on collagen fibrillogenesis in the skin. J Dermatol Sci 2007;47:217-26.

28. Honardoust D, Varkey M, Marcoux Y, Shankowsky HA, Tredget EE. Reduced decorin, fibromodulin, and transforming growth factor- $\beta 3$ in Deep dermis leads to hypertorphic scarring. J Burn Care Res 2012;33:218-27.

29. Honardoust D, Varkey M, Hori K, Ding J, Shankowsky HA, Tredget EE. Small leucine-rich proteoglycans, decorin and fibromodulin, are reduced in postburn hypertrophic scar. Wound Repair Regen 2011;19:368-78.

30. Monfort J, Tardif G, Reboul P, Mineau F, Roughley P, Pelletier JP, et al. Correction: Degradation of small leucine-rich repeat proteoglycans by matrix metalloprotease13: identification of a new biglycan cleavage site. Arthritis Res Ther 2013;15:401

31. Li W1, Tang L, Xiong Y, Zhou X, Wu L. The chondroprotective effects of dehydroepiandrosterone probably exerted by its conversion to estradiol. J Steroid Biochem Mol Biol 2013;134:15-22.

32. Soo C, Hu FY, Zhang X, Wanq Y, Beanes $\mathrm{SR}$, Lorenz MH, et al. Differential expression of fibromodulin, a transforming growth factor-beta modulator, in fetal skin development and scarless repair. Am J Pathol 2000; 157:423-33.

33. Scoff A, Rivera AA, Mathis JM, Moore ST, Banerjee NS, Everts M. Effect of adenoviral mediated overexpression of fibromodulin on human dermal fibroblasts and scar formation in full-thickness incisional wounds. J Mol Med (Berl) 2007;85:481-96.

34. He D, Yang C, Chen M, Yang X, Li L. Effects of soft tissue injury to the temporomandibular joint: report of 8 cases. Br J Oral Maxillofac Surg 2013;51:58-62. 